\title{
Parents' experiences of introducing
} toddlers to fruits and vegetables through repeated exposure, with and without prior visual familiarization to foods: evidence from daily diaries

\section{Article}

Accepted Version

Creative Commons: Attribution-Noncommercial-No Derivative Works 4.0

Houston-Price, C., Owen, L., Kennedy, O. and Hill, C. (2019) Parents' experiences of introducing toddlers to fruits and vegetables through repeated exposure, with and without prior visual familiarization to foods: evidence from daily diaries. Food Quality and Preference, 71. pp. 291-300. ISSN 09503293 doi: https://doi.org/10.1016/j.foodqual.2018.08.003 Available at https://centaur.reading.ac.uk/76278/

It is advisable to refer to the publisher's version if you intend to cite from the work. See Guidance on citing.

Published version at: https://doi.org/10.1016/j.foodqual.2018.08.003

To link to this article DOI: http://dx.doi.org/10.1016/j.foodqual.2018.08.003

Publisher: Elsevier

All outputs in CentAUR are protected by Intellectual Property Rights law, including copyright law. Copyright and IPR is retained by the creators or other copyright holders. Terms and conditions for use of this material are defined in the End User Agreement. 


\section{www.reading.ac.uk/centaur}

\section{CentAUR}

Central Archive at the University of Reading

Reading's research outputs online 


\section{Accepted Manuscript}

Parents' experiences of introducing toddlers to fruits and vegetables through repeated exposure, with and without prior visual familiarization to foods: Evidence from daily diaries

Carmel Houston-Price, Laura H. Owen, Orla B. Kennedy, Claire Hill

PII: S0950-3293(18)30383-5

DOI: https://doi.org/10.1016/j.foodqual.2018.08.003

Reference:

FQAP 3552

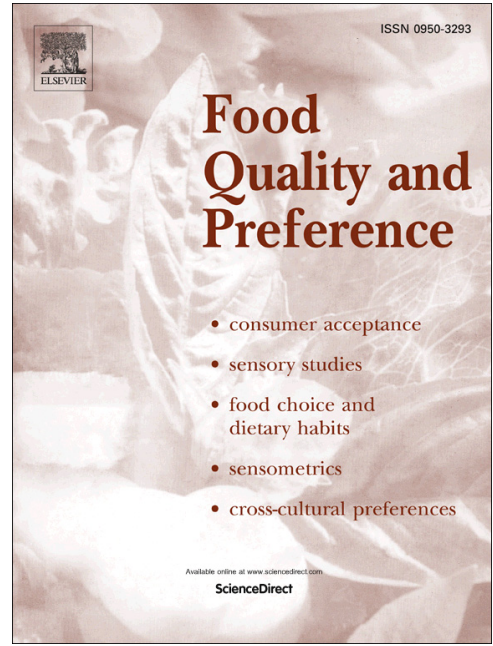

To appear in:

Food Quality and Preference

Received Date:

16 May 2018

Revised Date:

31 July 2018

Accepted Date:

4 August 2018

Please cite this article as: Houston-Price, C., Owen, L.H., Kennedy, O.B., Hill, C., Parents' experiences of introducing toddlers to fruits and vegetables through repeated exposure, with and without prior visual familiarization to foods: Evidence from daily diaries, Food Quality and Preference (2018), doi: https://doi.org/10.1016/j.foodqual. 2018.08.003

This is a PDF file of an unedited manuscript that has been accepted for publication. As a service to our customers we are providing this early version of the manuscript. The manuscript will undergo copyediting, typesetting, and review of the resulting proof before it is published in its final form. Please note that during the production process errors may be discovered which could affect the content, and all legal disclaimers that apply to the journal pertain. 
Parents' experiences of introducing toddlers to fruits and vegetables through repeated exposure, with and without prior visual familiarization to foods: Evidence from daily diaries

\author{
Carmel Houston-Price ${ }^{1}$
}

Laura H. Owen ${ }^{1}$

Orla B. Kennedy²

\title{
Claire Hill ${ }^{1}$
}

${ }^{1}$ School of Psychology and Clinical Language Sciences, University of Reading, Early Gate, Whiteknights, Reading, RG6 6AL, UK

${ }^{2}$ Hugh Sinclair Human Nutrition Unit, Department of Food and Nutritional Sciences, University of Reading, PO Box 226, Whiteknights, Reading, RG6 6AP, UK

Please address all correspondence to: Professor C. Houston-Price, School of Psychology \& Clinical Language Sciences, University of Reading, Earley Gate, Whiteknights, Reading, RG6 6AL. Tel: (+44) 0118 3787918. Email: c.houston-price@ reading.ac.uk

This work was supported by the Economic \& Social Research Council (grant reference RES000-22-3891)

Declaration of interest: None. 


\begin{abstract}
While repeated exposure is an established method for inducing food acceptance in young children, little is known about parents' experiences of repeatedly offering new or disliked foods at home. In this study, parents kept structured diary records during a 15-day period in which they offered their 2-year-old child daily tastes of one fruit and one vegetable. We explored how children's acceptance of foods (measured in terms of willingness to taste, liking and intake) and the ease and enjoyment of the process for parents changed from the early (days 1-5) to middle (days 6-10) to later (days 11-15) phases of exposure. In addition, we explored whether prior visual familiarization to foods affected children's behavior and/or parents' experiences during exposure. Families were randomly assigned to look at a picture book about one to-be-exposed food for the two weeks prior to the exposure phase ('fruit book' and 'vegetable book' groups) or to a control group, who did not receive a book. Measures obtained from parents' diary records revealed increases in willingness to taste and intake of vegetables and increased liking of both fruits and vegetables with greater exposure. Prior visual familiarization to vegetables further boosted children's willingness to taste and liking of vegetables, and the ease and enjoyment of introducing these for parents. Children's acceptance of foods and parents' positivity during exposure predicted children's liking and intake of foods 3 months later. Results confirm the potential for vegetable picture books to support parents in engaging with repeated exposure regimes and in successfully introducing vegetables into toddlers' diets.
\end{abstract}

Keywords: picture books, taste exposure, fruit and vegetables, children, parents, diary records 


\section{Introduction}

Giving pre-school children repeated opportunities to taste new or disliked foods is an established technique for increasing their liking and consumption of fruits and vegetables (for recent reviews of this literature, see Appleton et al., 2016; Holley, Farrow \& Haycraft, 2017; Nekitsing, Hetherington \& Blundell-Birtill, 2018). The effectiveness of repeated taste exposure is robust across a variety of contexts: positive outcomes have been reported to result from exposures delivered by researchers in laboratory settings (Birch \& Marlin, 1982; Birch, McPhee, Shoba, Pirok, \& Steinberg, 1987), by teachers and caretakers in nurseries and schools (Ahern, Caton, Blundell \& Hetherington, 2014; Bouhlal, Issanchou, Chabanet \& Nicklaus, 2014; Caton et al., 2013, 2014; de Wild, de Graaf \& Jager, 2013, 2017; Hausner, Olsen \& Moller, 2012; Wardle, Herrera, Cooke \& Gibson, 2003b) and by parents in the home (Fildes, van Jaarsveld, Wardle \& Cooke, 2014; Wardle et al., 2003a). Moreover, simply providing repeated taste opportunities is often as effective as manipulations that combine repeated exposure with other strategies hypothesized to boost liking of a food, such as flavorflavor learning or flavor-nutrient learning (Bouhlal et al., 2014; Caton et al., 2013; de Wild et al., 2013; Hausner et al., 2012). Offering a food repeatedly therefore appears to be a straightforward answer to the question of how to increase young children's fruit and vegetable consumption.

Why, then, have efforts to improve the quality of children's diets met with such limited success? Among preschoolers, vegetable intake in particular continues to fall well short of healthy eating guidelines (e.g. National Diet \& Nutrition Survey, 2014). As gatekeepers to the foods available to young children, parents are responsible for providing children with sufficient opportunities to taste healthy foods. Their failure to do so might result from a lack of awareness of the need to provide repeated exposures. Although recent health campaigns encourage parents to offer toddlers a wide variety of fruits and vegetables (e.g. 5 A Day, NHS, 2003; Change 4 Life, Public Health England, 2009; Healthy Start, Department of Health, Social Services \& Public Safety, 2011; NHS Choices, 2018), the message that disliked foods are likely to become accepted if they are offered repeatedly is typically not highlighted in such guidance. Alternatively, parents might be aware of, but unable to meet, recommendations to offer repeated exposures. Some studies suggest that 10 or more exposures may be needed before a food will be accepted (e.g. Birch \& Marlin, 1982; Birch et 
al., 1987; Remington, Añez, Croker, Wardle \& Cooke, 2011); the persistence needed to offer a disliked food this many times may be too much to ask of parents (Carruth \& Skinner, 2000). Indeed, Carruth, Ziegler, Gordon \& Barr (2004) found that only $5 \%$ of parents of children under 2 years provided the recommended 10+ opportunities to taste new foods. In the same study, the majority of parents offered a new food only three to five times before deciding that their child did not like it, while around a quarter gave up after offering a food only once or twice. Work by Caton and colleagues is encouraging in reporting increased intake of an unfamiliar vegetable among toddlers after only five exposures (Caton et al., 2013, 2014). Nevertheless, most children are unlikely to receive sufficient exposures to new foods for these to be accepted.

Parents clearly require support in providing repeated taste exposures in the home. Yet, little is known about parents' experiences of introducing new foods, or about why they might desist so readily. Indeed, no study to date has tracked parents' efforts to provide repeated exposures to new or disliked foods. The current study aimed to fill this gap, by collecting structured diary reports of parents' experiences of introducing their 2-year-old child to two disliked or unfamiliar foods - one fruit and one vegetable - at home. Every day during a taste exposure phase lasting 15 consecutive days, parents were asked to record whether they offered their child a taste of each food and, if so, whether their child was willing to taste the food, and how easy it was to persuade the child to taste it, how much the child liked the food, how much of it the child ate, and how much the parent enjoyed the taste session. Availability of the food was ensured by arranging regular home deliveries of both target foods. Parents' diary records provided rich information about their experiences of the exposure regime, enabling us to elucidate the trajectory of children's changing food acceptance over time.

The collection of these diary records formed part of a larger, longitudinal study (see also Owen, Kennedy, Hill \& Houston-Price, 2018), allowing us to explore a second question of interest. Specifically, the design of the study enabled us to ask whether parents' and children's experiences of engaging in repeated exposure differed if, prior to introducing a food, they had spent a period looking at a picture book about it. Previous research has shown that visual familiarization to fruits and vegetables through picture books can increase toddlers' interest in looking at familiarized foods (Houston-Price et al., 2009a; Heath, Houston-Price \& Kennedy, 2010, 2014), their willingness to taste the foods (Houston-Price, Butler \& Shiba, 2009) and their intake of the foods (Heath et al., 2014) when these are later 
offered in laboratory taste tests. The current study enabled us to explore whether prior visual familiarization to foods also supports parents in their efforts to offer repeated exposures to foods at home. To this end, families were randomly allocated to one of three experimental groups. Those in 'fruit book' and 'vegetable book' groups were sent a picture book about their child's target fruit or vegetable, respectively, and asked to look at this with their child for a few minutes every day during the fortnight prior to the taste exposure phase. A control group were not sent a book, but participated in the subsequent taste exposure phase alongside the two book groups. We examined whether parents' diary reports of the introduction process differed for children who were first visually familiarized to foods. We expected to see greater positivity in both children's behaviors and parents' experiences of exposure for foods to which children had been visually familiarized through picture books.

Our primary hypotheses, therefore, relate to the following two research questions:

1) What is the typical time course of acceptance/ rejection of disliked or unfamiliar foods when toddlers are offered repeated exposures to these at home?

We hypothesized that children's acceptance of a food (indexed by their willingness to taste, liking and intake of the food) would become more positive with increasing exposure, and that these changes would be accompanied by higher levels of parent positivity towards taste sessions (indexed by the ease with which children were persuaded to taste foods and parent enjoyment). Based on the literature, we expected changes to be seen when children had tasted foods more than 10 times. However, in line with Caton et al.'s $(2013,2014)$ findings, we also explored evidence of changes after fewer exposures. We therefore divided the intervention into early (days 1-5), middle (days 6-10) and later phases (days 11-15), and compared the measures collected during these phases.

2) Does prior visual familiarization to a food support parents in introducing it?

Based on the findings of earlier studies, we hypothesized that children's acceptance of foods (willingness to taste, liking and intake) and parents' positivity towards taste sessions (ease of persuasion and enjoyment) would be greater if children had first seen the food in a book. 
In addition to these primary questions, we explored whether any demographic or other background measures collected prior to the intervention predicted children's acceptance of foods or parents' experiences during the taste exposure phase. We hypothesized that more neophobic children, and fussy eaters, would show less acceptance of foods during the intervention, and that their parents would report less positive experiences. Finally, follow-up measures collected three months post-intervention allowed us to explore whether the diary measures collected during the taste exposure phase predicted longer-term changes in children's liking and intake of the targeted foods.

\section{Methods}

\subsection{Participants}

Families of 127 children (61 boys) aged 18 to 24 months (mean age at baseline $=21.6$ months; $\mathrm{SD}=1.6$ ) were recruited from the University of Reading's database of parents who had expressed an interest in participating in research with their child $(n=103)$, from adverts placed on parenting websites $(n=13)$, leaflets placed in local nurseries $(n=7)$ or by word of mouth $(n=4)$. Families were randomly assigned to one of three experimental groups: a 'fruit book' group ( $n=42 ; 22$ males); a 'vegetable book' group ( $n=46 ; 22$ males); or a control group ( $n=39 ; 17$ males).

Of the 127 families who participated in the intervention, completed diary records of families' experiences during the taste exposure phase were returned by parents of 100 children (50 boys; mean age post-intervention $=23.2$ months, $\mathrm{SD}=1.7$ ). These 100 families were the participants in the current study. Full demographic data for participating parents and children are provided in Table 1. The distribution across the three experimental groups of the 27 families who did not return diary records did not differ from chance, $\chi^{2}(2)=2.46, p=.29$, Cramer's $V=.14$ (fruit book: $n=10$; vegetable book: $n=12$; control group: $n=5$ ).

Of the 100 participating families, follow-up questionnaires were returned 3 months after the intervention by parents of 74 children ( 36 boys; mean age at follow-up $=26.6$ months, $\mathrm{SD}=$ 1.5). The distribution across the three groups of the 26 families who failed to respond at follow-up again did not differ from chance, $\chi^{2}(2)=1.79, p=.41$, Cramer's $V=.13$ (fruit book: $n=11$; vegetable book: $n=8$; control group: $n=7$ ). 
The study was scrutinized and allowed to proceed by the University of Reading's's Research Ethics Committee (Reference no. REC 10/01) and was carried out in accordance with the Code of Ethics of the World Medical Association (Declaration of Helsinki). Parents (in all cases, mothers) gave informed consent to their and their child's participation.

\subsection{Measures and Coding}

A demographic questionnaire was distributed at baseline to obtain the following: child's age, gender and ethnic origin; parent's educational level, marital status and household income; number of children living at home, and frequency of family meals. At baseline and at the three-month follow-up, measures were also collected relating to children's liking and intake of fruits and vegetables (including the targeted foods) and attitudes towards foods in general. Measures collected included the Food Familiarity \& Liking Questionnaire (Heath et al., 2014), Child Food Frequency Questionnaire (Livingstone, 2010), Child Food Neophobia Scale (CFNS) (Pliner, 1994) and the Food Fussiness subscale of the Children's Eating Behavior Questionnaire (CEBQ:FF) (Wardle, Guthrie, Sanderson \& Rapoport, 2001). Details of the coding of these questionnaires are reported in Owen et al. (2018).

Parents were asked to complete a structured diary record of their experiences during the taste exposure phase. A booklet was provided to each family for this purpose; this comprised two pages of instructions and advice about conducting the taste exposure phase and a further 30 pages on which parents were asked to record their experiences each day ( 1 page for each food, per day). Each page displayed a picture of the relevant food and asked the same 9 questions. Parents were instructed to answer each question by circling the relevant response option or by writing in the space provided.

The questions asked about each food each day, and the coding of these, were as follows:

(1) whether the target food was offered ('yes' = 1, 'no' =0);

(2) what time the food was offered;

(3) the context of the tasting session (mealtime/ snack);

(4) whether anything unusual affected that taste session (e.g. illness/ away from home); 
(5) if the child was offered the food, how s/he responded (5 response options: 'refused to touch food' $=1$, 'touched food but did not put in/ near mouth' $=2$, 'put food on lips but not in mouth' = 3, 'put food in mouth but spat out/ did not eat' $=4$, 'ate food' $=5$ );

(6) how easy it was to persuade the child to taste the food (5 response options: 'very difficult' $=1$, 'quite difficult' $=2$, 'it was okay' $=3$, 'quite easy' $=4$, 'very easy' $=5$ );

(7) how much the parent enjoyed the tasting session (5 response options: 'very unpleasant' $=1$, 'quite unpleasant' $=2$, 'it was okay' $=3$, 'quite enjoyable' $=4$, 'very enjoyable' $=5$ ), (8) if the child ate the food, how much s/he ate (4 response options: 'a tiny taste/nibble' = 1, ' 1 tsp/a bite' = 2, '1 dessertspoon/several bites' = 3, 'a child-sized portion or more' $=4$ ); (9) if the child tasted the food, how much s/he liked it (5 response options: 'disliked a lot' $=1$, 'disliked a bit' $=2$, 'neither liked nor disliked' $=3$, 'liked a bit' $=4$, 'liked a lot' $=5$ ).

\subsection{Procedure}

Upon recruitment, parents were asked to specify one fruit and one vegetable they would like their child to eat but that their child refused to eat. Parents who were unable to identify a disliked fruit $(\mathrm{N}=15)$ or vegetable $(\mathrm{N}=8)$ were asked to suggest an unfamiliar food instead. The two foods identified by parents were designated the target foods for that child (see the Appendix for the list of foods chosen by parents).

\subsubsection{Baseline Measures}

Parents were sent a set of questionnaires at baseline to collect demographic information and measures of children's liking and intake of the target foods and attitudes towards new foods (see section 2.2). Measures were completed and returned by post or collected online.

\subsubsection{Visual Familiarization Phase}

Parents of children in the 'fruit book' and 'vegetable book' groups were sent a paperback picture book about their child's target fruit or vegetable, respectively. Each book contained 8 pages of color photographs and information about the food in the format of a simple 'farm to fork' photo story showing how the food grows, how it appears in shops, and what it looks like when it is cut open, prepared and served. Parents were asked to look at the book with their child for a few minutes every day for two weeks. Families in the control group did not receive a book and were told that they would be contacted two weeks later. 


\subsubsection{Taste Exposure Phase}

Immediately following the visual familiarization phase, children in all groups participated in two weeks of taste exposure to their two target foods. Parents were asked to offer children a taste of both foods every day for 15 consecutive days. Families received home deliveries of the target foods three times during this period (on approximately the $1^{\text {st }}, 6^{\text {th }}$ and $11^{\text {th }}$ day of exposure); each delivery provided enough for at least five servings. Fresh foods were provided where possible but tinned, frozen or dried foods were substituted if fresh foods were not available. Parents were asked to provide a child-sized portion of each food every day, defined as the amount that would fit into the palm of their child's hand (NHS, 2011). Parents were invited to prepare the foods how they liked, and to provide them at whatever time of day was convenient, as a snack or part of a meal. However, they were asked to prepare foods in the same way each day (e.g. boiled carrots every day, rather than boiled one day and raw the next) and to avoid mixing them with other foods, to ensure that the food was not hidden. On each day of exposure, parents were asked to complete the relevant pages of the diary booklet immediately after the taste session had ended.

\subsubsection{Follow-Up Questionnaires}

Approximately three months after the exposure intervention, parents were asked to complete the same set of questionnaires collected at baseline (except demographic items). Mean time between baseline and follow-up questionnaire completion was 15.0 weeks ( $\mathrm{SD}=2.0$ ). After the follow-up questionnaires had been returned, families in the control group were sent a book about the child's target fruit or vegetable to thank them for their participation.

\subsection{Coding of Measures and Approach to Analysis}

\subsubsection{Diary Measures}

Diary records were hand-coded as indicated above (see section 2.2) and recorded in spreadsheet format. Missing exposure days (when a parent reported that a food was not offered) were dealt with by realigning the data provided on subsequent exposure days, to ensure that reports were linked to the actual number of exposures offered (thus, if a food was not offered on day 5, the records for days 6-15 became the records for days 5-14 for that food). All other missing data were dealt with by excluding cases from affected analyses. 
The number of exposures to each food was calculated by summing responses to Question 1 (whether the target food was offered) over the entire 15 days of exposure. All other measures were computed as described below both across all 15 days of exposure and, separately, for the early (days 1-5), middle (6-10) and later (11-15) days of exposure, to allow changes over time to be explored.

Question 5 (if the child was offered the food, how s/he responded) was recoded to distinguish whether the food was tasted (responses 4 and 5, recoded as ' 1 ') or not (responses 1 to 3 , recoded as ' 0 ') and summed to produce a measure of the number of tastes experienced. As number of tastes was dependent on the number of exposures offered, we computed the proportion of offers tasted (by dividing number of tastes by the number of exposures) as the key measure of children's willingness to taste a food.

Total intake was computed by summing responses to Question 8 (if the child ate the food, how much s/he ate). Again, as total intake was dependent on the number of exposures, we computed the mean intake per offer (by dividing total intake by number of exposures) as the key measure of children's intake of the food.

Responses to Question 6 (how easy it was to persuade the child to taste the food), Question 7 (how much the parent enjoyed the tasting session) and Question 9 (if the child tasted the food, how much s/he liked it) were averaged to provide mean measures of ease of persuasion, parent enjoyment, and child's mean liking of the food, respectively.

Kolmogorov-Smirnov tests confirmed that measures were largely non-normally distributed; non-parametric analyses were therefore used to test hypotheses. Changes over time (early vs. middle vs. later days of exposure) were explored using Friedman tests for related samples, followed by Wilcoxon signed-rank tests to identify pairwise differences. Group differences (fruit book vs. vegetable book vs. controls) were investigated using Kruskal-Wallis H tests, followed by Mann Whitney U-tests of pairwise differences. Spearman's rank-order correlations were used to assess relationships between measures. Two-tailed tests were used in all analyses. 


\subsubsection{Baseline and Follow-Up Measures}

Full details of the coding and analysis of the questionnaire measures collected at baseline and at the follow-up conducted 3 months post-intervention are reported in Owen et al. (2018). These analyses highlighted changes in liking and consumption from baseline to follow-up as the most revealing long-term outcome measures. In line with this approach, we used Spearman's rank-order correlations to explore relationships between the diary measures collected during the taste exposure phase and the long-term outcomes of the intervention, as indexed by changes in children's liking and consumption of target foods from baseline to follow-up.

\section{Results}

\subsection{Preliminary Analyses}

Table 1 summarizes the demographic measures for the 100 families who kept diary records during the taste exposure phase. There were no differences between the three groups (fruit book, vegetable book, controls) on any measure collected at baseline (see Table 1).

\section{<Insert Table 1>}

Tables 2 and 3 present the median (and range) for each diary measure collected in relation to the target fruit and vegetable, respectively, aggregated over the 15 days of exposure. Kruskal Wallis tests confirmed that there were no differences between groups in the number of exposures parents provided to either the target fruit, $\chi^{2}(2)=3.13, p=.21$, or vegetable, $\chi^{2}(2)$ $=2.01, p=.37$. Thus, parents in the three groups adhered equally well to the instruction to offer their child a taste of both foods each day.

$<$ Insert Tables 2 and 3>

Three further sets of analyses were conducted to explore factors that might have influenced the success of the intervention. First, we explored the relationships between measures of children's acceptance of foods and measures of parents' positivity towards taste sessions, aggregated across the exposure period. As hypothesized, the key measures of child acceptance (proportion of offers tasted, mean intake per offer, mean liking) were all strongly 
positively correlated with the measures of parents' positivity (ease of persuasion, parent enjoyment) for both target foods (all Spearman's $r \mathrm{~s} \geq .48$, all $p \mathrm{~s}<.001$ ). Thus, parents found it easier and more enjoyable to provide repeated exposures when children were more willing to taste the foods, ate more of the foods and liked the foods more, and vice versa.

Second, we explored whether demographic or other background measures predicted children's food acceptance or parents' positivity during taste exposure (see Table 1 for the factors investigated). As expected, children's food attitudes at baseline were strong predictors of their acceptance of foods and parents' positivity towards taste sessions. Child Food Neophobia Scale scores predicted the proportion of offers tasted (fruits: Spearman's $r(99)=-$ $.35, p<.001$; vegetables: $r(99)=-.35, p<.001$ ), mean intake per offer (fruits: $r(99)=-.38, p<$ .001 ; vegetables: $r(99)=-.28, p=.008$ ), ease of persuasion (fruits: $r(99)=-.33, p=.001$; vegetables: $r(99)=-.30, p=.002$ ) and parents' enjoyment (fruits: $r(99)=-.26, p=.01$ ). An identical pattern of relationships was seen with CEBQ: Food Fussiness scores (all $p \mathrm{~s}<.05$ ). In addition, child ethnic origin was found to predict mean liking for vegetables; White British children were reported to like their target vegetable less than children in other ethnic groups, Mann Whitney $U=292, Z=2.82, p=.005$ (but note the small sample in the latter group, $N=$ 17). Diary measures were not related to any other measure collected at baseline (child age, gender, parent education, marital status, household income, $N$ of children, frequency of family meals, fruit and vegetable purchases, child fruit and vegetable intake; all $p s>.05$ ).

Third, we explored any differences in participants' experiences of introducing the two target foods (see Tables 2 and 3 for median values for each comparison). Although the median number of exposures to fruits and vegetables was 13 in each case, differences in the distributions of these variables meant that children received a larger number of exposures to fruits $($ mean $=13.02, \mathrm{SD}=1.97)$ than vegetables $($ mean $=12.30, \mathrm{SD}=2.32)$, Wilcoxon's $T=$ $27.30, Z=3.92, p<.001$. The proportion of offers tasted did not differ between food groups, $T$ $=44.00, Z=1.29, p=.20$, but mean intake per offer was greater for fruits, $T=43.65, Z=$ $2.99, p=.003$, as was mean liking, $T=30.67, Z=3.63, p<.001$. Parents also reported greater ease, $T=39.07, Z=3.05, p=.002$, and enjoyment, $T=39.13, Z=3.55, p<.001$, when offering fruits. Children therefore showed greater acceptance of fruits than vegetables during the exposure phase and parents reported more positive experiences of introducing fruits (see Figures 1 and 2). 
3.2 Changes in Food Acceptance with Repeated Taste Exposure

Our first hypothesis stated that children would show more positive behaviors towards foods with increasing exposure and that parents, as a result, would become more positive about taste sessions with exposure. To test this hypothesis, we first looked for relationships between the number of exposures children were offered to each food and overall measures of children's acceptance of foods (proportion of offers tasted, mean intake per offer, mean liking) and parents' positivity towards taste sessions (ease of persuasion, parent enjoyment.) The number of exposures to fruits was related to parents' enjoyment of fruit-tasting sessions, $r(100)=.24, p=.018$. However, there were no other significant relationships between number of exposures and the diary measures collected for either fruits or vegetables (all $p \mathrm{~s}>$ .05). Thus, the total number of exposures provided was not a robust predictor of children's acceptance of foods or of parents' positivity towards the intervention, likely due to parents' broad adherence to the instruction to offer both foods every day.

Next, we looked for within-participant changes in each diary measure over time, from the early (days 1-5) to middle (days 6-10) and later (days 11-15) days of exposure. As can be seen in Figure 1, measures of children's acceptance of foods tended to become slightly more positive with increasing exposure. For fruits, Friedman tests found no main effects of time on proportion of offers tasted, $\chi^{2}(2)=.74, p=.69$, mean intake per offer, $\chi^{2}(2)=2.49, p=.29$, or mean liking, $\chi^{2}(2)=3.05, p=.22$, although paired comparisons using Wilcoxon signedrank tests revealed significant increases in children's mean liking of fruits from the early to middle days of exposure, $Z=2.06, p=.039$. There were no significant effects of time on reported ease of persuading children to taste fruits, $\chi^{2}(2)=3.82, p=.15$, or on parents' enjoyment of offering fruits, $\chi^{2}(2)=1.73, p=.42$ (see Figure 2 ).

$<$ Insert Figures 1 and 2>

For vegetables, there was no main effect of time on proportion of offers tasted, $\chi^{2}(2)=4.58$, $p=.10$, mean intake per offer, $\chi^{2}(2)=2.38, p=.30$, or mean liking, $\chi^{2}(2)=5.61, p=.061$ (see Figure 1). However, paired comparisons revealed significant increases in the proportion of offers tasted, $Z=1.97, p=.049$, and mean intake per offer, $Z=2.26, p=.024$, from the middle to later days of exposure. There was also a significant increase in mean liking of 
vegetables from the early to later days of exposure, $Z=2.21, p=.027$. There were no changes over time in the reported ease of persuading children to taste vegetables, $\chi^{2}(2)=.05$, $p=.98$, or in parents' enjoyment of offering vegetables, $\chi^{2}(2)=.81, p=.67$ (see Figure 2).

These findings confirm that children's willingness to taste and intake of the targeted vegetable, and their liking of both the target fruit and vegetable, increased with repeated opportunities to taste these foods. However, parents as a group did not find taste sessions to become easier or more enjoyable over the course of exposure.

\subsection{Impact of Prior Visual Familiarization on Food Acceptance during Repeated Exposure}

The second hypothesis stated that children's behaviors towards foods during taste exposure and parents' positivity towards taste sessions would be enhanced by a period of looking at foods in a picture book before the exposure phase.

To test this hypothesis, we first grouped children according to whether they had received prior visual familiarization to their target fruit (fruit book group, $N=32$ ) or not (vegetable book and control groups combined, $N=68$ ). There were no differences between groups in the number of exposures provided to fruits, Mann Whitney $U=911.50, Z=-1.33, p=.18$, or in the proportion of offers tasted, $U=1008.00, Z=.59, p=.55$, mean intake per offer, $U=$ $1017.00, Z=.53, p=.60$, or mean liking, $U=742.50, Z=-.88, p=.38$, of the target fruit (see Figure 3). Similarly, there were no group differences in parents' reports of the ease of persuading children to taste fruits, $U=1071.50, Z=.12, p=.90$, or in parents' enjoyment of the fruit-tasting sessions, $U=1078.50, Z=-.07, p=.94$ (see Figure 4). There were also no differences between groups during any individual phase of exposure (all $p \mathrm{~s}>.05$ ).

$<$ Insert Figures 3 and 4>

When children were grouped according to whether they had received prior familiarization to their target vegetable (vegetable book group, $\mathrm{N}=34$ ) or not (fruit book and control groups combined, $\mathrm{N}=66$ ), there was again no difference between groups in the number of exposures provided, Mann Whitney $U=930.00, Z=1.42, p=.16$. However, the two groups of children showed differences on several measures of food acceptance (see Figure 3). Although the 
overall proportion of offers tasted, $U=923.00, Z=1.45, p=.15$, and mean intake per offer, $U=890.00, Z=1.70, p=.09$, did not differ significantly between groups, children who had seen vegetable books tasted a greater proportion of offers during the middle days of exposure than children who had not, $U=744.00, Z=-2.52, p=.012$. Children who had seen vegetable books also showed significantly higher mean liking of the vegetable than those who had not, both overall, $U=516.00, \mathrm{Z}=2.65, p=.008$, and separately in the early, $U=431.00, Z=$ $2.29, p=.022$, and later days of exposure, $U=173.00, Z=-2.47, p=.013$.

Parents also found it easier and more enjoyable to introduce vegetables following visual familiarization (see Figure 4). There were significant group differences in the reported ease of persuading children to taste the target vegetable, both overall, $U=771.00, Z=2.55, p=.011$, and during the early, $U=839.00, Z=2.06, p=.039$, middle, $U=676.50, Z=2.99, p=.003$, and later days of exposure, $U=514.00, Z=2.38, p=.017$, separately. Similarly, there were significant differences between groups in parents' enjoyment of vegetable tasting sessions, both overall, $U=735.00, Z=2.84, p=.004$, and in the middle, $U=690.00, Z=2.96, p=$ .003 , and later days of exposure, $U=488.50, Z=2.53, p=.012$, separately.

Thus, prior visual familiarization enhanced children's willingness to taste and liking of their target vegetable during repeated taste exposure, and made the process of introducing vegetables easier and more enjoyable for parents. There were no effects of prior visual familiarization to fruits.

\subsection{Relationships between Experiences during Taste Exposure and Outcomes at Follow-Up}

Of the 100 families who completed diaries during the taste exposure phase, 74 returned follow-up questionnaires about their child's eating behavior 3 months post-intervention, enabling us to explore whether families' experiences during the taste exposure regime were related to longer-term outcomes. There were no correlations between the number of exposures offered to foods during the intervention and long-term changes in children's liking or intake of the food (all $p \mathrm{~s}>.05$ ). However, all outcome measures (changes in liking and intake from baseline to follow-up, for both foods) were predicted by all three measures of children's acceptance of the food during the exposure regime (proportion of offers tasted, mean intake per offer, mean liking) and by both measures of parents' positivity towards taste sessions with the relevant food (ease of persuasion, parent enjoyment) (all $p \mathrm{~s}<=.01$ ). 


\section{Discussion}

The measures obtained from the diary records kept by parents in this study corroborate previous findings of increasing acceptance of new or disliked foods among young children with repeated taste exposure (Ahern et al., 2014; Birch \& Marlin, 1982; Birch et al., 1987; Bouhlal et al., 2014; Caton, et al., 2013, 2014; de Wild et al., 2013, 2017; Fildes et al., 2014; Hausner et al., 2012; Wardle et al., 2003a, 2003b; see Nekitsing, Hetherington \& BlundellBirtill, 2018, for a recent review). In addition, the study provides the first insight into parents' experiences of repeatedly offering children tastes of fruits and vegetables at home. Results also highlight the facilitatory role played by prior visual familiarization to foods; this was seen to enhance both the success of the repeated exposure regime for children and parents' positivity towards engaging with it. We discuss the unique contributions of the study in relation to these points in turn.

First, the study elucidates the typical time course of toddlers' acceptance of disliked or unfamiliar fruits and vegetables when they are offered daily tastes of these at home. Parents largely adhered to protocol instructions, offering children a taste of both target foods almost every day during the 15-day exposure period. As in other studies of repeated taste exposure (e.g. Bouhlal et al., 2014; Caton et al., 2013; Hausner et al., 2012; Wardle et al., 2003b), changes in children's willingness to taste, liking and intake of foods were seen to be gradual in nature (see Figure 1), rather than sharp increases in acceptance after a criterion number of exposures had been reached. However, when the intervention was divided into the early, middle and later periods of exposure, systematic patterns were evident in children's changing acceptance of foods, with effects most marked and consistent for vegetables. Children showed increases in their willingness to taste, liking and intake of their target vegetable during the final days of exposure (days 11-15), supporting previous claims that acceptance of a disliked or unfamiliar vegetable may require at least 10 exposures (Birch \& Marlin, 1982; Birch et al., 1987). Fruits were reported to be more liked after fewer taste exposures (by days 6-10).

Contrary to expectations, the process of introducing new foods was not reported to become easier or more enjoyable for parents as children became more accepting of foods. This cannot reflect parents' failure to notice children's increasingly positive behaviors towards foods; it was parents, after all, who reported the changes in children's willingness to taste, liking and 
intake of the foods. Furthermore, parents were sensitive to differences in children's acceptance of fruits and vegetables; they reported that children liked and ate more fruits than vegetables, and that it was easier and more enjoyable to introduce fruits. Parents were, therefore, sensitive to their children's likes and dislikes.

The lack of any change in parents' attitudes during the exposure regime might instead indicate that they found it burdensome to offer their child the same foods repeatedly, despite children's increasing acceptance of them. This is a matter of concern. The strong correlation between parents' overall enjoyment of fruit-tasting sessions and the number of times they offered fruits to their child suggests that parents' positivity towards engaging in repeated exposure might determine whether they provide sufficient exposures to bring about positive outcomes. It is therefore important to identify and tackle the causes of parents' lack of motivation to engage with exposure regimes. In this study, the intervention was made as easy as possible, with target foods delivered regularly to the home; as a result, although parents did not find it an enjoyable experience, the majority persisted to the end of the regime. However, had they not been participating in a research study, parents might have stopped providing taste opportunities earlier. If the difficulty lies in the inconvenience of providing the same foods every day, the burden might be reduced if parents were encouraged to offer a daily taste of whatever vegetables they are preparing for meals for other family members. Intermittent exposure regimes, in which children are offered tastes of foods every few days on an alternating basis, have been shown to be just as effective, or even more so, than regimes in which the same foods are offered every day (Ahern et al., 2014; Maier, Chabanet, Schaal, Issanchou \& Leithwood, 2007; Mennella, Nicklaus, Jagolino \& Yourshaw, 2008). Future work should therefore explore how exposure regimes might be made easier and more enjoyable for parents; a more flexible, intermittent exposure schedule targeting foods already being prepared for family meals may be one solution.

The study also demonstrated that the success of repeated exposure to vegetables was enhanced by prior familiarization to foods through picture books. Families assigned to look at books about vegetables for the two weeks prior to taste exposure reported benefits in terms of both children's acceptance of the vegetable during the exposure phase and in parents' positivity towards taste sessions involving vegetables. From the very earliest days of exposure, and throughout the intervention, children in the vegetable book group were reported to show greater liking of their target vegetable than children who had not seen 
vegetable books. Prior visual familiarization also made children more willing to taste their target vegetable during the middle period of the regime. These findings corroborate previous claims that visual familiarization supports food acceptance in toddlers (e.g. Houston-Price et al., 2009; Heath et al., 2014; Owen et al., 2018) and further confirm a role for picture books in supporting the introduction of vegetables into children's diets.

Questions remain about the mechanisms that underpin books' effects, however, and about the type of visual familiarization that is likely to be optimal. No study has so far directly compared the effects of the books used in the current study with other manipulations found to be effective in this age group. For example, positive outcomes have been reported among preschoolers who look at narrative story books about cartoon characters who grow strong after eating vegetables (de Droog, Buijzen, \& Valkenbury, 2014) or who engage in non-taste sensory play with foods (Coulthard \& Ahmed, 2017; Coulthard \& Sealy, 2017; Dazeley \& Houston-Price, 2015). Interestingly, hands-on tactile experience with foods has been shown to have a greater impact on children's willingness to taste and intake of foods than either playing with pictures of foods (Coulthard \& Ahmed, 2017) or observing someone else playing with the food (Coulthard and Sealy, 2017), suggesting that familiarity with foods in more than one sensory modality may be beneficial.

One component of the picture book intervention that remains uninvestigated, but likely to play a crucial role, is the involvement of parents. In the current study, parents were the agents of both the visual familiarization element of the intervention and the daily taste exposure regime. The extent to which parents' positivity towards the process determined its success is unclear; while measures of parents' attitudes and children's behaviors during the exposure regime were highly inter-correlated, whether this relationship is causal (and the direction of any causality) cannot be assumed. However, the measures collected during the taste exposure phase are revealing about books' effects on parents' experiences of engaging in repeated taste exposure. We found that parents' experiences closely matched their reports of children's acceptance of foods. That is, parents of children who had seen a vegetable book found it easier and more enjoyable to provide repeated exposures to the vegetable than did parents in other groups. The difference in ease was seen from the earliest days of exposure until the end of the intervention, while this group of parents' greater enjoyment of vegetable tasting sessions was most marked during the middle and later days of exposure. Whether the greater positivity shown by this group was due to their child's acceptance of their target vegetable or 
to the parent's own greater familiarity with the food remains unknown, however, and in need of further investigation.

In contrast to the positive results found for vegetables, familiarization to books about fruits had no discernible impact on children's acceptance of foods or parents' experiences of taste exposure. Parents' diary reports may shed some light on the cause of the difference in books' effectiveness towards fruits and vegetables. As shown in Figure 1, children were more accepting of fruits than vegetables from the outset. And, among the group as a whole, changes in liking of fruits were seen earlier during exposure than changes in liking of vegetables. It is likely that fruits' naturally sweeter taste underlies both these differences; by enhancing children's acceptance of fruits across the board, taste exposure leaves less room for any influence of visual familiarization. This hypothesis is congruent with previous findings showing that the effects of familiarization to foods through picture books are graded, with initially unfamiliar foods showing the largest effects, followed by disliked foods and then liked foods (Heath et al., 2010, 2014). Given that fruits were more liked than vegetables at the outset, we might expect to see weaker effects for fruits. In fact, no effects of visual familiarization at all were seen for fruits in this study. Conclusions about the benefits of picture books should therefore be restricted to the introduction of new or disliked vegetables. Given the evidence that vegetable intake is more protective against a range of life-threatening illnesses, and the rather more mixed picture in relation to fruit intake (Oyebode, GordonDseagu, Walker \& Mindell, 2014), it is arguably more appropriate for public health strategies to focus their efforts on children's vegetable consumption, regardless.

\subsection{Conclusions}

While further work is needed to explore how exposure tools might be made optimally effective for both children and parents, in the meantime health practitioners and parents should be made aware of the benefits of familiarizing children to foods prior to offering these at mealtimes, particularly if the goal is to increase the range of vegetables in toddlers' diets. 


\section{References}

Ahern, S.M., Caton, S.J., Blundell, P. \& Hetherington, M.M. (2014). The root of the problem: Increasing root vegetable intake in preschool children by repeated exposure and flavour flavour learning. Appetite, 80, 154-160.

Appleton, K.M., Hemingway, A., Saulais, L., Dinnella, C., Monteleone, E., Depezay, L. et al. (2016). Increasing vegetable intakes: Rationale and systematic review of published interventions. European Journal of Nutrition, 55 (3), 869-896. https://doi.org/10.1007/s00394-015-1130-8

Birch, L.L., \& Marlin, D.W. (1982). I don't like it; I never tried it: Effects of exposure on two-year-old children's food preferences. Appetite: Journal for Intake Research, 3, 353 360 .

Birch, L.L., McPhee, L., Shoba, B.C., Pirok, E., \& Steinberg, L. (1987). What kind of exposure reduces children's food neophobia? Looking vs. tasting. Appetite, 9, 171-178.

Bouhlal, S., Issanchou, S., Chabanet, C. \& Nicklaus, S. (2014). 'Just a pinch of salt': An experimental comparison of the effect of repeated exposure and flavour-flavor learning with salt or spice on vegetable acceptance in toddlers. Appetite, 83, 209-217.

Carruth, B.R., \& Skinner, J.D. (2000). Revisiting the picky eater phenomenon: Neophobic behaviors of young children. Journal of the American College of Nutrition, 19, 6, 771780.

Carruth, B.R., Ziegler, P.J., Gordon, A., \& Barr, S.I. (2004). Prevalence of picky eaters among infants and toddlers and their caregivers' decisions about offering a new food. Journal of the American Dietetic Association, 104, 57-64.

Caton, S.J., Ahern, S.M., Remy, E., Nicklaus, S., Blundell, P. \& Hetherington, M.M. (2013). Reptition counts: Repeated exposure increases intake of a novel vegetable in UK presschool children compared to flavour-flavour and flavour-nutrient learning. British Journal of Nutrition, 109 (11), 2089-2097.

Caton, S.J., Blundell, P., Ahern, S.M., Nikitsing, C., Olsen, A., Moller, P., .... Hetherington, M.M. (2014). Learning to eat vegetables in early life: The role of timing, age, and individual eating traits. PlosOne, https://doi.org/10.1371/journal.pone.0097609.

Coulthard, H. \& Ahmed, S. (2017). Non taste exposure techniques to increase fruit and vegetable acceptance in children: effects of task and stimulus type. Food Quality and Preference, 61 (Supplement C), 50-4. https://doi.org/10.1016/j.foodqual.2017.04.012 
Coulthard, H. \& Sealy, A. (2017). Play with your food! Sensory play is associated with tasting of fruits and vegetables in preschool children. Appetite, 113, 84-90. https://doi.org/10.1016/j.appet.2017.02.003

Dazeley, P. \& Houston-Price, C. (2015). Exposure to foods' non-taste sensory properties: A nursery intervention to increase children's willingness to try fruit and vegetables. Appetite, 84, 1-6. https://doi.org/10.1016/j.appet.2014.08.040

Department of Health, Social Sciences \& Public Safety (2011). Healthy start. Accessed on 25 October, 2017 at www.healthystart.nhs.uk.

de Droog, S.M., Buijzen, M., \& Valkenburg, P.M. (2014). Enhancing children's vegetable consumption using vegetable-promoting picture books: The impact of interactive shared reading and character-product congruence. Appetite, 73(Supplement C), 73-80. https://doi.org/10.1016/j.appet.2013.10.018.

de Wild, V.W.T., de Graaf, C., \& Jager, G. (2013). Effectiveness of flavour nutrient learning and mere exposure as mechanisms to increase toddler's intake and preference for green vegetables. Appetite, 64, 89-96.

de Wild, V.W.T., de Graaf, C. \& Jager, G. (2017). Use of different vegetable products to increase preschool-aged chidlren's preference for and intake of a target vegetable: A randomized controlled trial. Journal of the Academy of Nutrition \& Dietetics, 117 (6), $859-866$.

Fildes, A., van Jaarsveld, C.H.M., Wardle, J. \& Cooke, L. (2014). Parent-administered exposure to increase children's vegetable acceptance: A randomized controlled trials. Journal of the Academy of Nutrition \& Dietetics, 114 (5), 881-888.

Hausner, H., Olsen, A. \& Moller, P. (2012). Mere exposure and flavour-flavour learning increase 2-3 year-old children's acceptance of a novel vegetable. Appetite, 58 (3), $1152-$ 1159 .

Heath, P.M., Houston-Price, C. \& Kennedy, O.B. (2010). Can visual exposure impact on children's visual preferences for fruit and vegetables? Proceedings of the Nutrition Society, 69 (OCE6), E422.

Heath, P., Houston-Price, C. \& Kennedy, O.B. (2014). Let's look at leeks! Picture books increase toddlers' willingness to look at, taste and consume unfamiliar vegetables. Frontiers in Psychology, 5 (191), 1-11.

Holley, C.E., Farrow, C. \& Haycraft, E. (2017). A systematic review of methods for increasing vegetable consumption in early childhood. Current Nutrition Reports, 6 (2), 157-170, https://doi.org/10.1007/s13668-017-0202-1 
Houston-Price, C., Burton, E., Hickinson, R., Inett, J., Moore, E., Salmon, K., \& Shiba P. (2009a). Picture book exposure elicits positive visual preferences in toddlers. Journal of Experimental Child Psychology, 104, 89-104.

Houston-Price, C., Butler, L., \& Shiba, P. (2009b). Visual exposure impacts on toddlers' willingness to taste fruit and vegetables. Appetite, 53, 450-453.

Livingstone, K., M. (2010, April). Visual exposure using picture books improves children's preferences for fruits and is affected by neophobia status and parental influences (BSc Project). University of Reading.

Maier, A., Chabanet, C., Schaal, B., Issanchou, S. \& Leithwood, P. (2007). Effects of repeated exposure on acceptance of initially disliked vegetables in 7-month-old infants. Food Quality \& Preference, 18, 1023-1032.

Mennella, J.A., Nicklaus, S., Jagolino, A.L. \& Yourshaw, L.M. (2008). Variety is the spice of life: Strategies for promoting fruit and vegetable acceptance during infancy. Physiology \& Behavior, 94, 29-38.

National Diet and Nutrition Survey (2014). NDNS: Results from years 1 to 4 combined of the rolling programme for 2008 and 2009 to 2011 and 2012: Report. Public Health England. Retrieved October 24, 2017, from www.gov.uk/government/publications.

Nekitsing, C., Hetherington, M.M. \& Blundell-Birtill, P. (2018). Developing healthy food preferences in preschool children through taste exposure, sensory learning, and nutrition education. Current Obesity Reports, 7 (1), 60-67, https://doi.org/10.1007/s13679-018$\underline{0297-8}$

NHS (2003). 5 a day. Accessed on 25 October, 2017 at www.nhs.uk/livewell/5aday.

NHS (2011). 5 a day portion sizes. Retrieved January 8, 2012, from http://www.nhs.uk/Livewell/5ADAY/Pages/Portionsizes.aspx

NHS Choices (2018). Your pregnancy and baby guide: What to feed young children. https://www.nhs.uk/conditions/pregnancy-and-baby/understanding-food-groups/\#fruitand-vegetables Accessed on 22/03/2018.

Owen, L.H., Kennedy, O.B., Hill, C. \& Houston-Price, C. (2018). Peas, please! Food familiarization through picture books helps parents introduce vegetables into toddlers' diets. Appetite, 128, 32-43. https://doi.org/10.1016/j.appet.2018.05.140.

Oyebode, O., Gordon-Dseagu, V., Walker, A. \& Mindell, J.S. (2014). Fruit and vegetable consumption and all-cause, cancer and CVD mortality; Analysis of Health Survey for England data. Journal of Epidemiology \& Community Health, 68, 856-862.

Pliner, P. (1994). Development of measures of food neophobia in children. Appetite, 23, 147- 
163.

Public Health England (2009). Change 4 life. Accessed 25 October, 2017, at www.nhs.uk/change4life.

Remington, A., Añez, E., Croker, H., Wardle, J., \& Cooke, L. (2012). Increasing food acceptance in the home setting: Arandomized controlled trial of parent-administered taste exposure with incentives. American Journal of Clinical Nutrition, 95 (1) 72-77, https://doi.org/10.3945/ajen.111.024596

Wardle, J., Cooke, L., Gibson, E.L., Sapochnik, M., Sheiham, A., \& Lawson, M. (2003a). Increasing children's acceptance of vegetables: A randomized trial of parent-led exposure. Appetite, 40, 155-162.

Wardle, J., Guthrie, C. A., Sanderson, S., \& Rapoport, L. (2001). Development of the children's eating behavior questionnaire. Journal of Child Psychology and Psychiatry, 42, 963-970.

Wardle, J., Herrera, M.L., Cooke, L., \& Gibson, E.L. (2003b). Modifying children's food preferences: The effects of exposure and reward on acceptance of an unfamiliar vegetable. European Journal of Clinical Nutrition, 57, 341-348. 


\section{Appendix}

The number of times each fruit and vegetable was chosen by parents as a 'target' food

\begin{tabular}{|c|c|c|c|}
\hline Fruits & $\begin{array}{c}\text { Frequency of } \\
\text { selection }\end{array}$ & Vegetables & $\begin{array}{c}\text { Frequency of } \\
\text { selection }\end{array}$ \\
\hline Apple & 15 & Artichoke & 1 \\
\hline Apricot & 4 & Asparagus & 4 \\
\hline Avocado & 2 & Aubergine & 1 \\
\hline Banana & 5 & Broccoli & 17 \\
\hline Blueberries & 2 & Broad beans & 1 \\
\hline Cherries & 3 & Brussels sprouts & \\
\hline Clementine & 2 & Butternut squash & 2 \\
\hline Grapefruit & 1 & Cabbage & 3 \\
\hline Grapes & 4 & Carrots & 16 \\
\hline Kiwi fruit & 7 & Cauliflower & 8 \\
\hline Mango & 3 & Courgette & 4 \\
\hline Melon & 4 & Cucumber & 8 \\
\hline Nectarine & 2 & Green beans & 6 \\
\hline Orange & 4 & Lettuce & 2 \\
\hline Papaya & & Mushroom & 3 \\
\hline Peach & 4 & Parsnip & 2 \\
\hline Pear & 4 & Peas & 4 \\
\hline Pineapple & 10 & Peppers & 2 \\
\hline Plum & 2 & Runner beans & 1 \\
\hline Pomegranate & 1 & Spinach & 2 \\
\hline Raspberries & 7 & Swede & 1 \\
\hline Satsuma & 3 & Sweet potato & 1 \\
\hline Strawberries & 9 & Sweetcorn & 1 \\
\hline Tomato & 1 & Tomato & 9 \\
\hline Total & 100 & & 100 \\
\hline
\end{tabular}


Table 1. Demographic and background measures collected at baseline for participants who provided diary records $(N=100)$. Unless otherwise indicated, measures reported are means (and standard deviations).

\begin{tabular}{|c|c|c|c|c|}
\hline \multirow[b]{2}{*}{$\begin{array}{l}\text { Demographic / } \\
\text { background measures }\end{array}$} & \multicolumn{3}{|c|}{ Experimental Group } & \multirow[b]{2}{*}{ Group Comparison } \\
\hline & $\begin{array}{l}\text { Fruit } \\
\text { Book }\end{array}$ & $\begin{array}{l}\text { Vegetable } \\
\text { Book }\end{array}$ & $\begin{array}{l}\text { Control } \\
\text { Group }\end{array}$ & \\
\hline Child age & $21.9(1.6)$ & $21.9(1.6)$ & $21.2(1.4)$ & $F(2,97)=1.99, p=.14$ \\
\hline Child gender ( $\%$ male $)$ & 56.3 & 47.1 & 47.1 & $\chi^{2}(2)=.74, p=.69$ \\
\hline Child ethnicity (\% White & 81.3 & 85.3 & 82.4 & $\chi^{2}(2)=.21, p=.90$ \\
\hline \multicolumn{5}{|l|}{ British) } \\
\hline $\begin{array}{l}\text { Parent education (\% } \\
\text { degree) }\end{array}$ & 62.5 & 52.9 & & $\chi^{2}(2)=1.10, p=.58$ \\
\hline Marital status (\% married) & 77.4 & 79.4 & 73.5 & $\chi^{2}(2)=.34, p=.84$ \\
\hline Household income (\% & 50.0 & 51.6 & 45.2 & $\chi^{2}(2)=.28, p=.87$ \\
\hline \multicolumn{5}{|l|}{$£ 50 \mathrm{k}+\mathrm{pa})$} \\
\hline $\mathrm{N}$ children in home & $1.74(.68)$ & $1.76(.71)$ & $1.62(.74)$ & $F(2,95)=.39, p=.68$ \\
\hline Frequency of family meals & $13.2(3.4)$ & $13.9(3.4)$ & $11.8(4.6)$ & $F(2,90)=2.46, p=.09$ \\
\hline Weekly fruit purchases & $31.8(10.3)$ & $31.0(7.6)$ & $28.6(9.8)$ & $F(2,97)=1.06, p=.35$ \\
\hline $\begin{array}{l}\text { Weekly vegetable } \\
\text { purchases }\end{array}$ & $(11.8)$ & $37.2(9.3)$ & $37.3(9.5)$ & $F(2,97)=1.00, p=.37$ \\
\hline Target fruit purchases & $1.22(.71)$ & $1.29(.72)$ & $1.12(.81)$ & $F(2,97)=.48 p=.62$ \\
\hline $\begin{array}{l}\text { Target vegetable } \\
\text { purchases }\end{array}$ & $1.59(.62)$ & $1.55(.75)$ & $1.38(.78)$ & $F(2,97)=.79, p=.46$ \\
\hline Child's daily fruit intake & $4.19(2.5)$ & $3.80(2.1)$ & $3.45(2.0)$ & $F(2,93)=.90, p=.41$ \\
\hline Child daily veg intake & $3.28(1.6)$ & $3.74(2.0)$ & $3.29(1.8)$ & $F(2,94)=.68, p=.51$ \\
\hline Child Food Neophobia & $13.7(5.3)$ & $14.5(3.9)$ & $13.2(4.2)$ & $F(2,96)=.74, p=.48$ \\
\hline Scale score & & & & \\
\hline $\begin{array}{l}\text { CEBQ: Food Fussiness } \\
\text { score }\end{array}$ & $15.8(5.0)$ & $16.9(4.1)$ & $15.6(4.5)$ & $F(2,97)=.80, p=.46$ \\
\hline
\end{tabular}


Table 2. Median (and range) for each diary report measure collected relating to target fruits, by experimental group, and for children overall. See Measures and Coding sections for full details of the computation of each measure. Intake was reported on a scale from 0 (none) to 4 (a child-sized portion or more). Liking, Ease of Persuasion and Parent Enjoyment were reported on a scale from 1 (strongly negative) to 5 (strongly positive).

\begin{tabular}{|c|c|c|c|c|}
\hline \multirow{3}{*}{$\begin{array}{l}\text { Measures relating to } \\
\text { Target Fruits }\end{array}$} & \multicolumn{3}{|c|}{ Experimental Group } & \\
\hline & \multirow[t]{2}{*}{ Fruit Book } & \multirow[t]{2}{*}{ Vegetable Book } & \multirow[t]{2}{*}{ Controls } & \\
\hline & & & & \\
\hline \multirow[t]{2}{*}{ Number of tastes offered } & 14 & 13 & 13 & 13 \\
\hline & $(9-15)$ & $(5-15)$ & $(8-15)$ & $(5-15)$ \\
\hline \multirow[t]{2}{*}{ Number of tastes experienced } & 9 & 10 & 8.5 & 9 \\
\hline & $(0-15)$ & $(0-15)$ & $(0-15)$ & $(0-15)$ \\
\hline \multirow[t]{2}{*}{ Proportion of offers tasted } & 0.72 & 0.71 & 0.69 & 0.71 \\
\hline & $(0-1)$ & $(0-1)$ & $(0-1)$ & $(0-1)$ \\
\hline \multirow[t]{2}{*}{ Total intake of food } & 16.5 & 13 & 23 & 16 \\
\hline & $(0-59)$ & $(0-60)$ & $(0-60)$ & $(0-60)$ \\
\hline \multirow[t]{2}{*}{ Mean intake per offer } & 1.4 & 1.0 & 1.6 & 1.4 \\
\hline & $(0-3.9)$ & $(0-4)$ & $(0-4)$ & $(0-4)$ \\
\hline \multirow[t]{2}{*}{ Mean child liking } & & 4.1 & 3.9 & 4.0 \\
\hline & $-5)$ & $(1-5)$ & $(1-5)$ & $(1-5)$ \\
\hline \multirow{2}{*}{ Mean ease of persuasion } & 3.1 & 3.1 & 3.3 & 3.2 \\
\hline & $(1.1-5)$ & $(1.2-5)$ & $(1-5)$ & $(1-5)$ \\
\hline \multirow{2}{*}{ Mean parent enjoyment } & 3.3 & 3.4 & 3.5 & 3.4 \\
\hline & $(2.1-5)$ & $(2.2-5)$ & $(1-4.9)$ & $(1-5)$ \\
\hline
\end{tabular}


Table 3. Median (and range) for each diary report measure collected relating to target vegetables, by experimental group, and for children overall. See Measures and Coding sections for full details of the computation of each measure. Intake was reported on a scale from 0 (none) to 4 (a child-sized portion or more). Liking, Ease of Persuasion and Parent Enjoyment were reported on a scale from 1 (strongly negative) to 5 (strongly positive).

\begin{tabular}{|c|c|c|c|c|}
\hline \multirow{3}{*}{$\begin{array}{l}\text { Measures relating to } \\
\text { Target Vegetable }\end{array}$} & \multicolumn{3}{|c|}{ Experimental Group } & \\
\hline & \multirow[t]{2}{*}{ Fruit Book } & \multirow[t]{2}{*}{ Vegetable Book } & \multirow[t]{2}{*}{ Controls } & All \\
\hline & & & & Children \\
\hline \multirow[t]{2}{*}{ Number of tastes offered } & 13 & 12 & 13 & 13 \\
\hline & $(6-15)$ & $(5-15)$ & $(5-15)$ & $(5-15)$ \\
\hline \multirow[t]{2}{*}{ Number of tastes experienced } & 7 & 9 & r & 8 \\
\hline & $(0-14)$ & $(0-14)$ & $(0-15)$ & $(0-15)$ \\
\hline \multirow[t]{2}{*}{ Proportion of offers tasted } & 0.57 & 0.79 & 0.50 & 0.67 \\
\hline & $(0-1)$ & $(0-1)$ & $(0-1)$ & $(0-1)$ \\
\hline \multirow[t]{2}{*}{ Total intake of food } & 5 & 16 & 11 & 12 \\
\hline & $(0-47)$ & $(0-55)$ & $(0-51)$ & $(0-55)$ \\
\hline \multirow[t]{2}{*}{ Mean intake per offer } & 0.44 & 1.4 & 1.0 & 1.0 \\
\hline & $(0-3.9)$ & $(0-3.9)$ & $(0-4)$ & $(0-4)$ \\
\hline \multirow[t]{2}{*}{ Mean child liking } & & 3.8 & 3.0 & 3.2 \\
\hline & & $(1-5)$ & $(1-5)$ & $(1-5)$ \\
\hline \multirow{2}{*}{ Mean ease of persuasion } & 2.6 & 3.3 & 2.6 & 2.8 \\
\hline & $(1.0-4.8)$ & $(1.0-4.9)$ & $(1.1-4.8)$ & $(1.0-4.9)$ \\
\hline \multirow[t]{2}{*}{ Mean parent enjoyment } & 3.0 & 3.3 & 3.1 & 3.1 \\
\hline & $(2.2-5.0)$ & $(2.0-5.0)$ & $(1.1-4.8)$ & $(1.1-5.0)$ \\
\hline
\end{tabular}


Figure 1. Mean reported child behaviors (with standard error bars) towards target fruits and vegetables during the early (days 1-5), middle (days 6-10) and later (days 11-5) phases of taste exposure. Panel (a): the proportion of offers tasted of each food (computed by dividing number of tastes by the number of exposures). Panel (b): mean intake per offer of each food (computed by summing reported total intake and dividing this by number of exposures); scale ranged from 0 (none) to 4 ('a child-sized portion or more'). Panel (c): mean liking of each food; scale ranged from 1 ('disliked a lot') to 5 ('liked a lot').

(a)

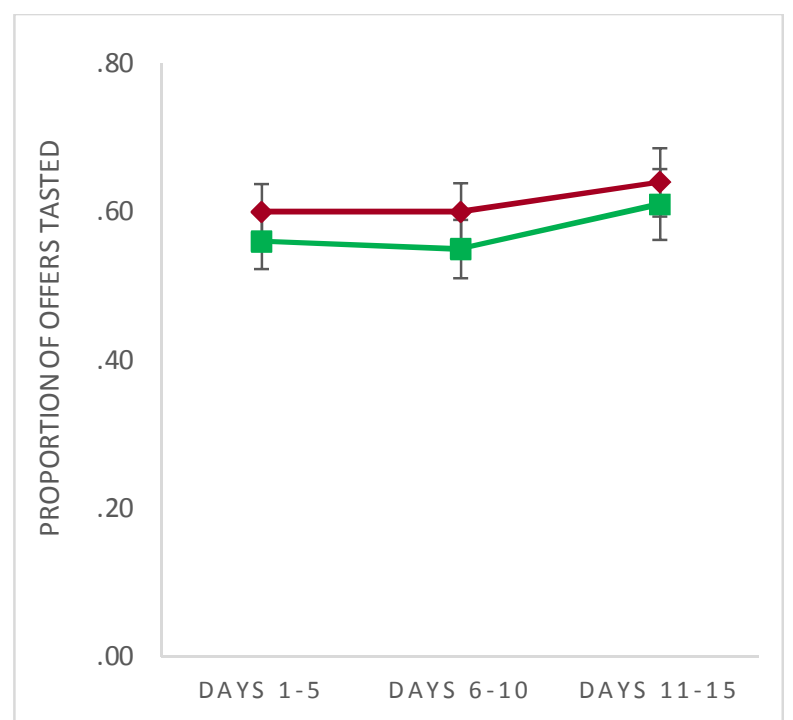

(b)

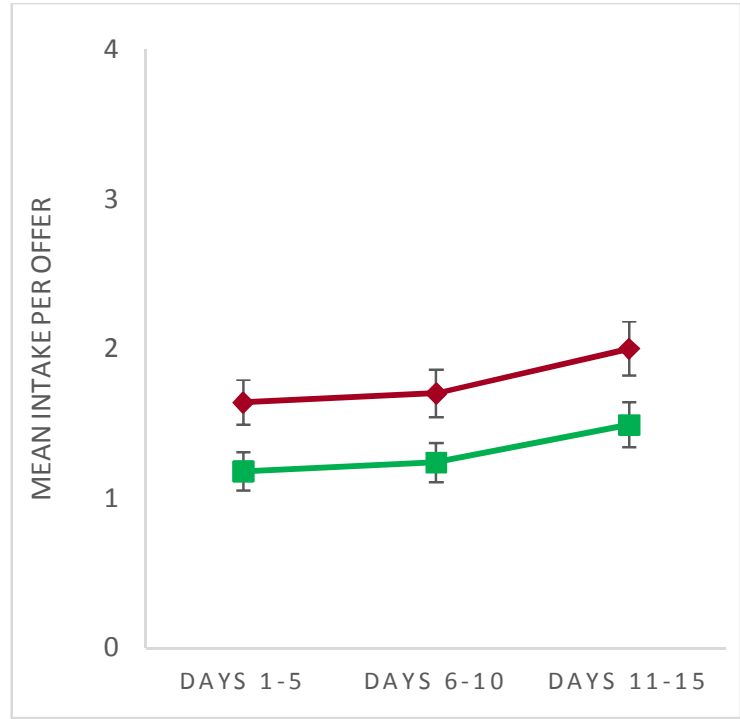

(c)

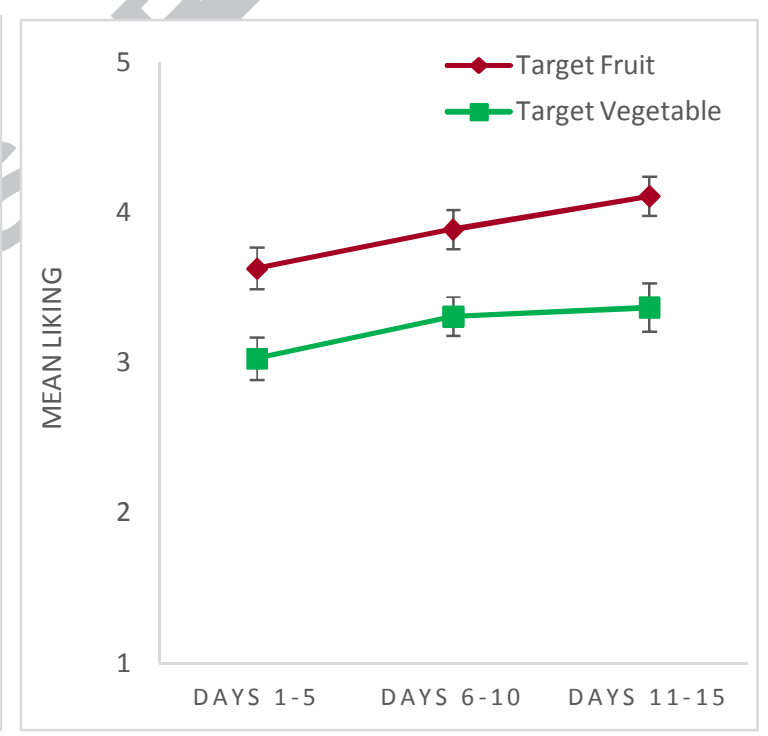


Figure 2. Mean reported attitudes of parents (with standard error bars) towards introducing target fruits and vegetables during the early (days 1-5), middle (days 6-10) and later (days 115) phases of taste exposure. Panel (a): mean ease of persuading children to taste each food; scale ranged from 1 ('very difficult') to 5 ('very easy'). Panel (b): mean parent enjoyment of taste sessions; scale ranged from 1 ('very unpleasant') to 5 ('very enjoyable').

(a)

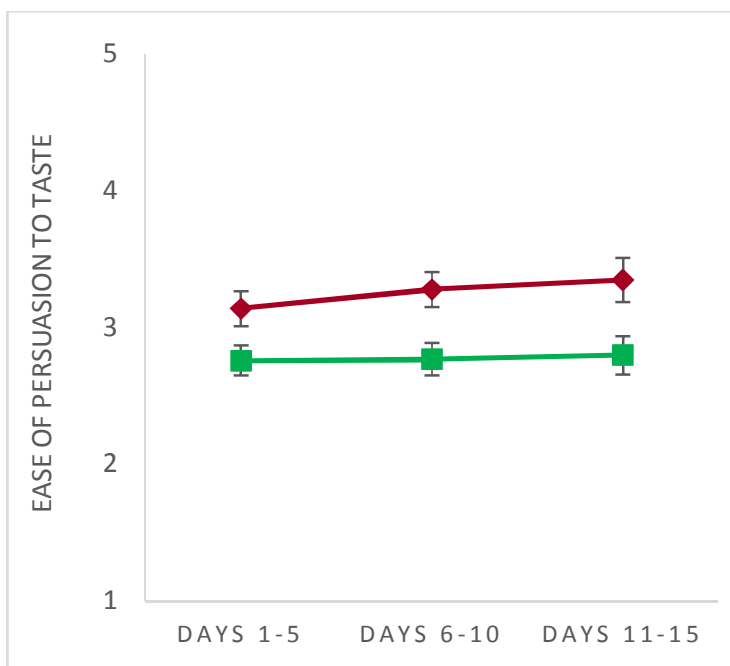

(b)

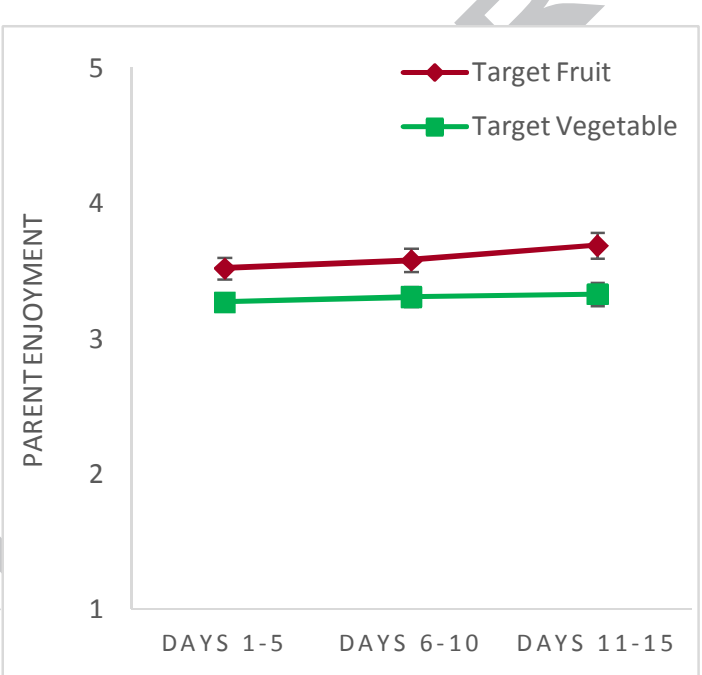


Figure 3. Mean reported child behaviors (with standard error bars) towards target foods, grouped according to whether children saw a book about the target fruit $(\mathrm{N}=32)$ or not $(\mathrm{N}=$ 68) (left side of panel), or according to whether they saw a book about the target vegetable $(\mathrm{N}=34)$ or not $(\mathrm{N}=66)$ (right side of panel). Panel (a): the proportion of offers tasted of each food (computed by dividing number of tastes by the number of exposures). Panel (b): mean intake per offer of each food (computed by summing reported total intake and dividing this by number of exposures); scale ranged from 0 (none) to 4 ('a child-sized portion or more'). Panel (c): mean liking of each food; scale ranged from 1 ('disliked a lot') to 5 ('liked a lot').

(a)

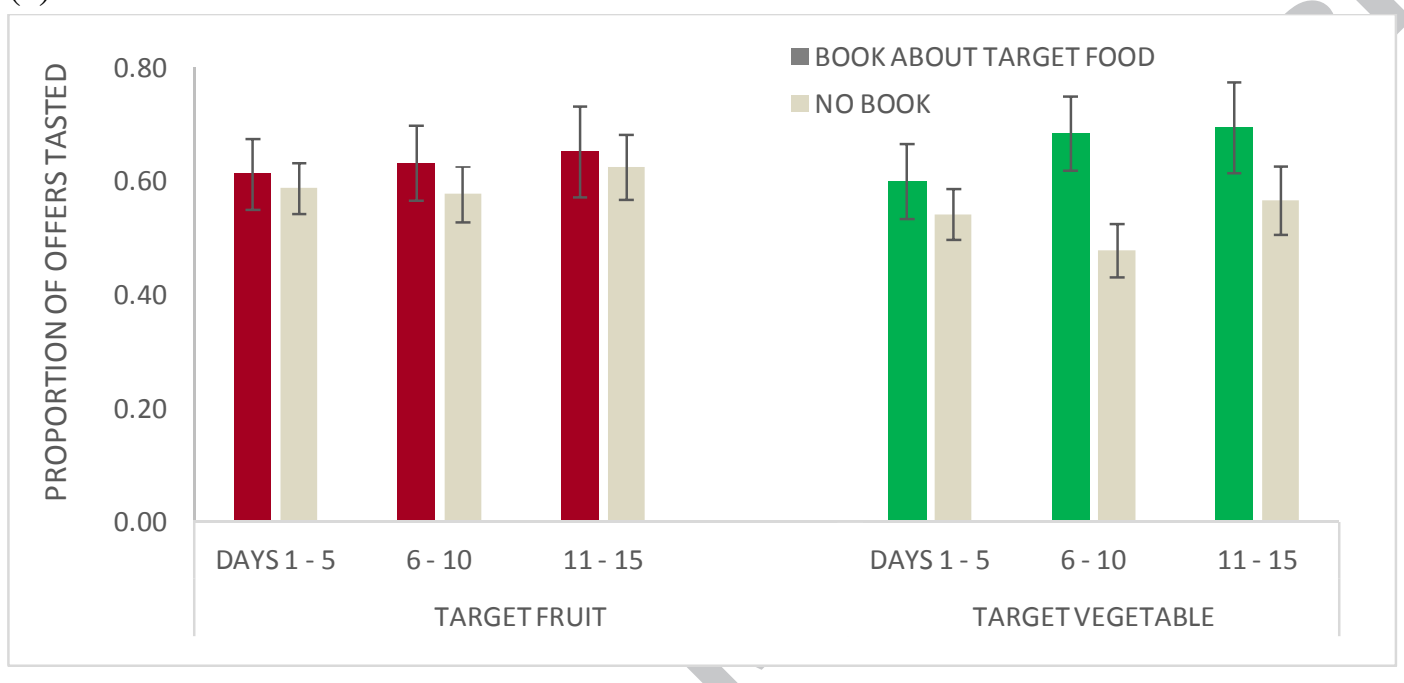

(b)

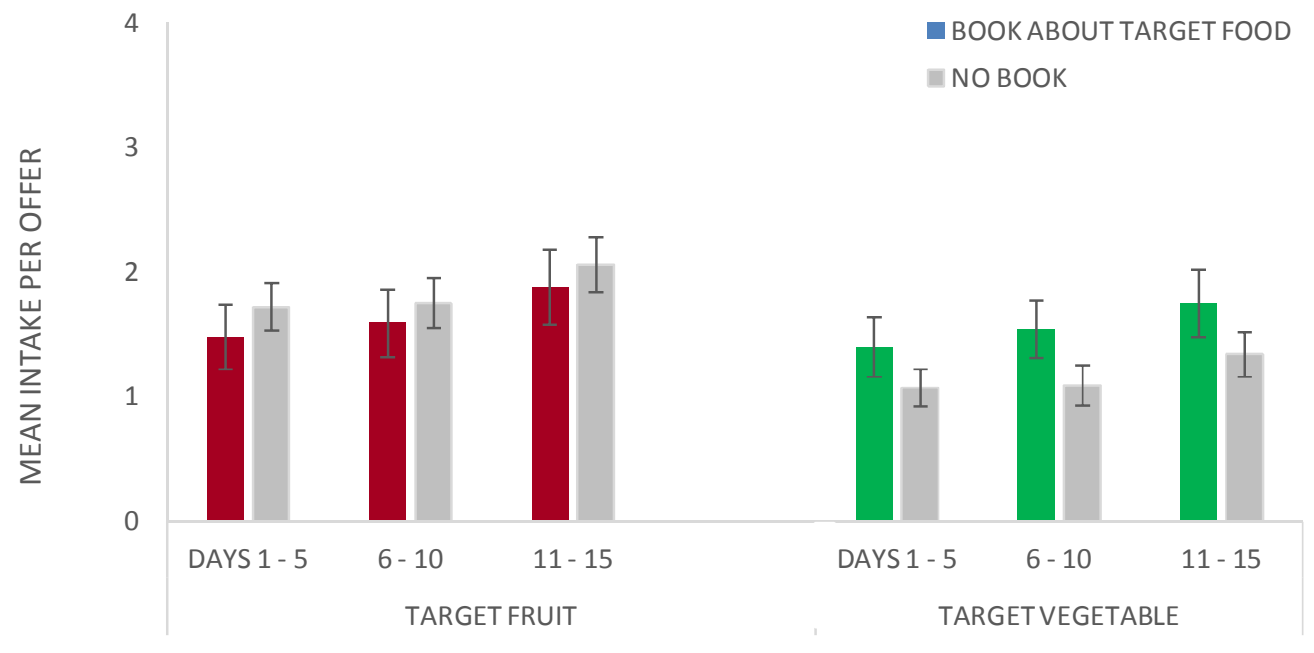


(c)

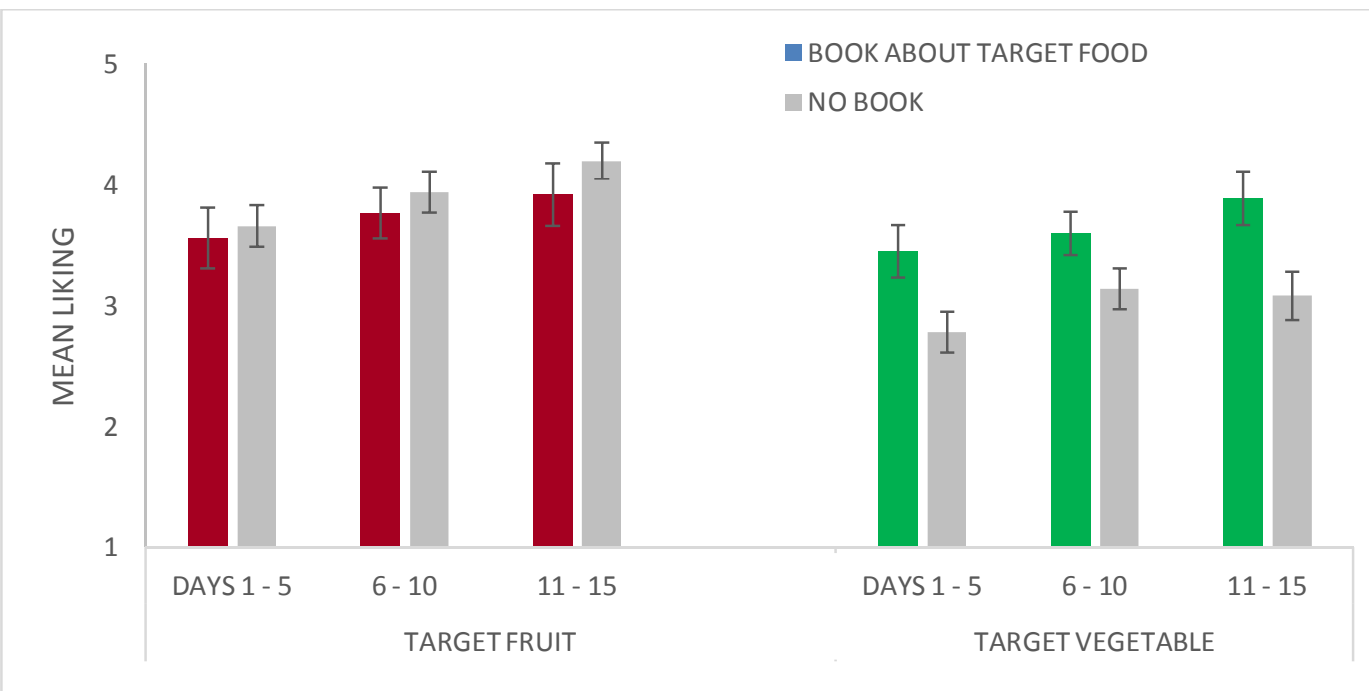


Figure 4. Parents' reported attitudes (with standard error bars) towards introducing target foods, grouped according to whether families saw a book about the fruit $(\mathrm{N}=32)$ or $\operatorname{not}(\mathrm{N}=$ 68) (left side of panel), or according to whether they saw a book about the vegetable $(\mathrm{N}=34)$ or not $(\mathrm{N}=66)$ (right side of panel). Panel (a): mean ease of persuading children to taste each food; scale ranged from 1 ('very difficult') to 5 ('very easy'). Panel (b): mean parent enjoyment of taste sessions; scale ranged from 1 ('very unpleasant') to 5 ('very enjoyable').

(a)

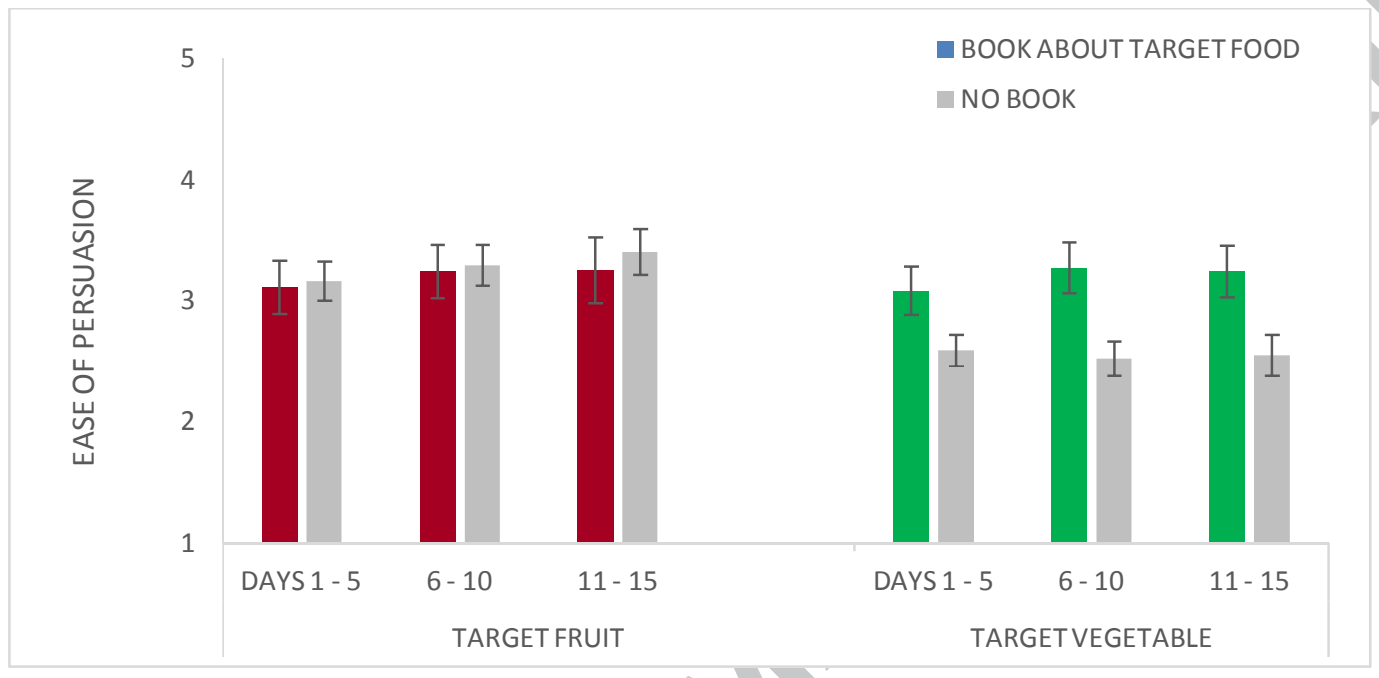

(b)

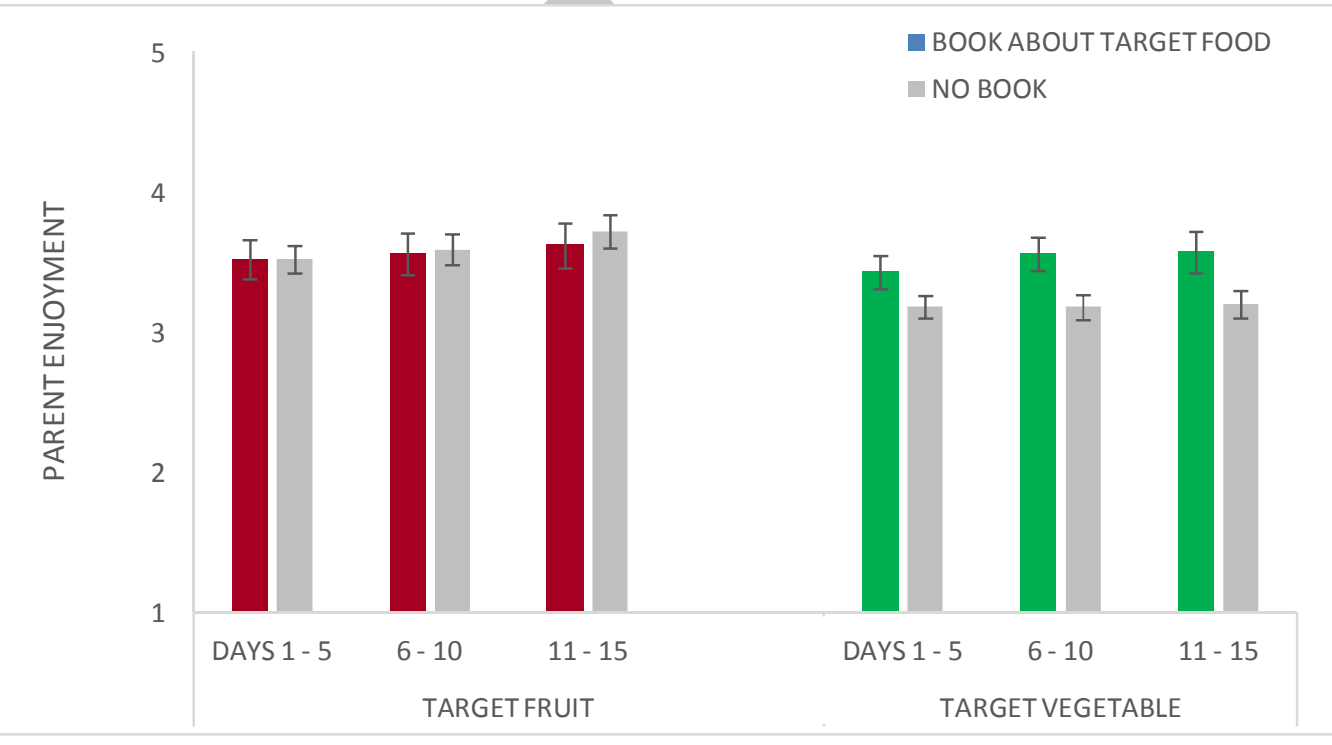


Highlights

- First study to document parents' experiences of repeatedly offering foods at home

- First study to explore how picture books affect the success of repeated exposure

- Disliked fruit and vegetables became more accepted by children with exposure

- Parents found engaging in taste exposure easier after sharing vegetable books

- Seeing picture books about vegetables also boosted children's acceptance of these 